Thomas McGinn, MD, MPH

Mount Sinai School of Medicine, Mount Sinai

Medical Center, New York, New York

\section{Helping Hospitalists Achieve Academic Stature}

A ccelerating the development of clinical research in academic hospitalist programs is a worthwhile goal if pursued with clarity, objectivity, and a thorough understanding of the process and its implications. In their articles, Flanders et al. ${ }^{1}$ and Wright et al. $^{2}$ identify major barriers to growing academic hospitalist programs. These barriers include the need for protected time, the shortage of trained research faculty, the lack of infrastructure, and the limited availability of senior mentors. Both Flanders et al. and Wright et al. offer smart and innovative ways of addressing these issues. However, building an academic program from the ground up is more complex and challenging than it may seem at first glance. It takes time, patience, creativity, diplomacy, and the ability to recruit collaborators and advocates who are willing to share infrastructure and resources.

Although both articles add significantly to the discussion of strategies for creating an academic hospitalist program, they are unclear about the definition of academic in this context. The term academic is often misunderstood to be synonymous with research. However, research is just one component of an academic program, which also includes education, quality improvement (QI), administration, and program development. It may be helpful, therefore, to replace academic with scholarship, which can be defined as a process that involves peer review and dissemination of ideas at local, regional, and national levels. Scholarship also goes beyond research, encompassing education and other areas such as QI. Although academic programs are not necessarily involved with funded research, there is usually an expectation of peer review, through either presentations at regional and national meetings or publication. For the purposes of this discussion, the term academic hospitalist program will be defined broadly to include any program affiliated with a university that is involved in the teaching of residents and medical students and whose faculty is required to participate in a promotions process.

All members of an academic division should be expected to participate in scholarship, whether it is education, QI projects, or research. If there is a strong expectation that traditional National Institute of Health (NIH) funded research will take place, this expectation must come with sufficient resources. Without infrastructure for research and investment in research faculty, procuring NIH funds for research is not a reasonable expectation. Organizers of hospitalist programs currently within academic divisions of general internal medicine should consider ways to better integrate programs into the existing research infrastructure in their divisions. For either freestanding hospitalist programs or programs within academic divisions of general internal medicine, investments in infrastructure and faculty are 
needed to nurture this area of research and build an academic focus in hospital medicine. However, if obtaining NIH research funds is not the expectation and resources are not available for hospitalists or for any other division or department at that institution, then academic expectations should focus on other pursuits. Examples include participation in the education and QI initiatives.

For programs with expectations of both funded research and other scholarship, a successful program will most likely include a small core of skilled clinical researchers working closely with well-trained clinical educators, all of whom are involved in scholarship. Both clinical educators and researchers need to be continuously developing, and to reach their full potential, all should have access to infrastructure that supports these activities, including resources such as MPH-level project managers, research assistants, database managers, and, most importantly, appropriate mentors.

Clinician educators must be both proficient clinicians and dedicated teachers. Ideally, they should have strong familiarity with educational theory in addition to skills in hands-on teaching. Their responsibilities include mastering the skills that students need, staying up to the minute in their areas of expertise, and serving as role models in their attitudes toward patients, colleagues, and their work. ${ }^{3}$ Many hospitalists may not have these skills when they begin, often fresh out of residency, and will need help developing them.

\section{PROTECTED TIME}

Protected time is crucial to the success of any academic program. Finding this time presents a challenge for any clinical group, but the challenge is exacerbated for hospitalists, who face tremendous pressure to serve full-time clinical jobs with little emphasis on academic elements such as education, QI, and participation in funded research. As both Wright et al. ${ }^{2}$ and Flanders et al. ${ }^{1}$ point out, to build a group of well-developed academic clinician educators, academic hospitalists not on track for funding need to be given adequate protected time to participate in committees, sharpen their teaching skills, develop QI projects that can be converted to scholarships, participate in research, and present at national and regional meetings.

The requirements of protected time for researchers are more challenging than those for edu- cators. Building a newly funded research unit within a hospitalist group, as with any group, will entail hiring fellowship trained faculty with significant protected time (approximately $80 \%$ ) to give them time to obtain funding such as a $\mathrm{K}$ award and eventually become independent investigators with RO1 grant funding. Building research units requires support from collaborators with infrastructure and mentors already in place that can be tapped during the incubation stage of the academic program. For most hospitalist programs, infrastructure and mentors will be found in their divisions of general internal medicine.

Protected time should be considered an integral element of academic hospitalist positionsnot a perk-as long as the time is used responsibly and productively. As both Wright et al. ${ }^{2}$ and Flanders et al. ${ }^{1}$ correctly point out, herein lies the major challenge of creating any kind of academic program: How will the program support protected time for both educators and researchers? In most instances, significant seed money will be needed to support junior faculty over the first few years of their careers. It is noteworthy that building a federally funded hospital medicine research program will be particularly difficult in today's economy because funding levels at the NIH, Agency for Healthcare Research and Quality, Health Resources and Services Administration, and other traditional funders of clinical research either are flat or have been reduced dramatically.

To many Academic Medical Centers (AMC), it may not be immediately obvious why a strong Academic Hospitalist program is in their economic best interest. Hospitalist programs may confront consistently high levels of turnover and a shrinking supply of general internists. The associated high costs of hiring new, junior faculty include the time and effort needed to interview, credential, train, and most importantly build familiarity with the complex systems encountered in maneuvering through a hospital, especially one with widespread dissemination of electronic medical records for documentation and order entry. However, hospitalists provided with opportunities for academic development are more likely to stay on the job longer and perform at a higher level, providing convincing motivation for hospitals to invest in their academic hospitalist programs. Retaining high-quality hospitalists may be one of the most cost-efficient methods for an AMC to support a hospital medicine program. 


\section{STRATEGIES IN ACTION}

Flanders et al. ${ }^{1}$ point to a shortage of well-trained clinician investigators with a focus on inpatient research as a barrier to the development of academic hospitalist programming. They describe a strategy of collaboration with specialty groups. This highlights the importance of collaboration with more well-established research units as a key ingredient to building a new academic unit. Wright et al. $^{2}$ describe their mentorship program and how they created protected time for scholarship for hospitalists, including supporting mentors' time. These examples highlight another key benchmark of a viable academic program, mentoring, and the importance of ensuring that mentors have time for this essential effort.

However, it is critically important to remember that "all politics is local," to quote the late Tip O'Neill, long-time speaker of the US House of Representatives. What works in one setting may not work as well in a different context-hence the need for creativity and political acumen.

For example, although the specialty-group collaboration described by Flanders et al. ${ }^{1}$ may be helpful in one setting, other strategic alliances may work on a larger scale and over a longer time period. Most hospital medicine groups are currently within academic divisions of general internal medicine, where infrastructure and mentoring may already exist for both research and educational scholarship. In those cases, fostering interaction between the division's hospitalists and its researchers would be a critical first step. The programming and growth developed in this way can be leveraged to support ongoing academic activities by hospitalists rather than being limited to a single project.
In the Division of General Internal Medicine at Mount Sinai, which houses the academic hospitalists, building research entailed collaboration with the well-established Departments of Geriatrics and Health Policy, which had preexisting research infrastructure and mentors. At the same time, we developed a research fellowship program by applying jointly with the Division of General Pediatrics for federal grant support. Such diversity of collaboration enhanced our application.

\section{LOOKING AHEAD}

Putting the academic into academic hospitalist programs is the key to the future of hospital medicine. To be successful, one must consider all the issues described in light of available resources and the local and federal political landscape. As Flanders et al. $^{1}$ and Wright et al. $^{2}$ emphasize, collaboration will be the main component for success in the current academic landscape.

Address for correspondence and reprint requests: Thomas McGinn, Mount Sinai Medical Center, 17 E 102nd Street, Box 1087, New York, NY 10029; Telephone: 212-824-7505; Fax: 212-426-5108; E-mail: thomas.mcginn@ mountsinai.org

Received 6 June 2008; accepted 7 June 2008.

\section{REFERENCES}

1. Flanders S, Kaufman S, Nallamothu B, Saint S. The University of Michigan Specialist-Hospitalist Allied Research Program (SHARP): jumpstarting hospital medicine research. J Hosp Med. 2008;3(4):308-313.

2. Howell E, Kravet S, Kisuule F, Wright SM. An innovative approach to supporting hospitalist physicians towards academic success. J Hosp Med. 2008;3(4):314-318.

3. Branch WT, Kroenke K, Levinson W. The clinician-educator-present and future roles. J Gen Intern Med. 1997; 12(suppl 2):S1-S4. 